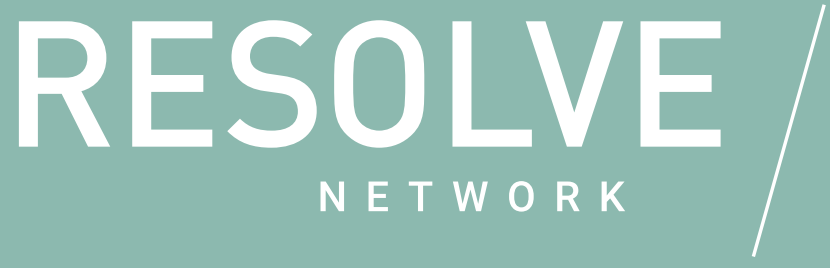

BILJEŠKAO POLITICI FEBRUAR 2021.

https://doi.org/ 10,37805/pn2021.2.wb

\title{
IMPERATIV REINTEGRACIJE DJECA POVRATNICI NA ZAPADNI BALKAN
}

\author{
ADRIAN SHTUNI
}

\section{SERIJA O ZAPADNOM BALKANU}

\section{${ }^{66}$ Nova istraživanja i programiranje o povratnicima iz Sirije $i$ Iraka tek se počinju baviti izazovom maloljetnih povratnika."}

\section{ČINJENICE UKRATKO Kontekst}

$\rightarrow$ Procjenjuje se da je ukupno 500 stranih boraca i članova porodica sa Zapadnog Balkana ostalo u Siriji i Iraku.

$\rightarrow$ Navodni muški borci čine oko jedne trećine osoba sa Zapadnog Balkana koje su ostale u Siriji. Djeca čine oko dvije trećine, a žene malu manjinu.

$\rightarrow$ Trenutna populacija stranih mladih osoba povezanih sa sukobom u Siriji zahtijeva proaktivno djelovanje, posebno uzimanje u obzir dobi i spola te odgovarajuća prilagođavanja reakcija politike u očekivanju njihove repatrijacije.
Od 2012. godine 1.070 državljana zemalja Zapadnog Balkana putovalo je kako bi živjelo i borilo se na teritorijima pod kontrolom terorističkih organizacija u Siriji i Iraku. Među njima je bilo otprilike 200 maloljetnih osoba u trenutku odlaska. Tokom godina, državljani zemalja Zapadnog Balkana dobili su još mnogo više djece u područjima zahvaćenim sukobima u Siriji i Iraku. Do kraja 2019. godine otprilike 485 osoba vratilo se svojim kućama, što Zapadni Balkan čini regijom s najvećom koncentracijom povratnika iz Sirije i Iraka u Europi. ${ }^{1}$ Još stotine osoba, uglavnom maloljetnika, i dalje su zatočene u neizvjesnim uslovima u Siriji, s

1 NAPOMENA: Dodatne podatke i detaljnu procjenu trenutnog stanja kontingenta stranih boraca i članova njihovih obitelji sa Zapadnog Balkana potražite u sljedećim materijalima: Adrian Shtuni, "Western Balkans Foreign Fighters and Homegrown Jihadis: Trends and Implications, Combating Terrorism," CTC Sentinel 12, br. 7 (13. august 2019):18-24, https://ctc. usma.edu/western-balkans-foreign-fighters-homegrownjihadis- t rends-implications/. 
neizvjesnim izgledima za repatrijaciju. ${ }^{2}$ Brojne zemlje se bore s tim što učiniti s državljanima koji su otputovali kako bi živjeli i borili se u takozvanom „kalifatu“ Islamske države (IS). Međutim, iskustvo i razumijevanje onoga što olakšava djelotvorno angažiranje u radu s povratnicima iz Sirije, posebno s djecom povratnicima, u početnoj je fazi. U ovoj bilješci o politici daju se preporuke o načinima pristupa rehabilitaciji i reintegraciji (RiR) djece povratnika na Zapadnom Balkanu uz kombiniranje nove dobre prakse s vodećim načelima konvencija, međunarodnih ugovora i protokola koji se fokusiraju na prava djece.

\section{Zatočenički logori, početne repatrijacije i tekući izazovi}

Nakon sloma fizičkog „kalifata“ IS-a, desetine hiljada boraca i članova porodica nakon predaje drže se u prenatrpanim kurdskim pritvorskim objektima i logorima s interno raseljenim osobama (IRL). U kampu Al-Hol, u kojem je smješten najveći broj članova porodica boraca IS-a, u avgustu 2019. godine bilo je 68.823 osoba $^{3}$ - izvorno je bio zamišljen za smještaj otprilike sedam puta manje Ijudi. ${ }^{4} \mathrm{U}$ nedavnom izvještaju Vijeća Ujedinjenih nacija za ljudska prava uslovi u Al-Holu su opisani kao „žalosni i nehumani“. ${ }^{5}$ Od ukupne populacije u Al-Holu, otprilike 7000 osoba su maloljetni stranci uz 3000 žena iz otprilike 50 zemalja ${ }^{6}$ - uključujući stotine osoba sa Zapadnog Balkana.

Procjenjuje se da je ukupno 500 stranih boraca i članova porodica sa Zapadnog Balkana ostalo u Siriji i Iraku. Navodni muški borci čine otprilike trećinu ovog kontingenta sa Zapadnog Balkana, dok djeca čine oko dvije trećine, a žene malu manjinu. Mnogi od tih boraca i članova porodica žele se vratiti u svoje zemlje.

Do sada, mnoge vlade nisu bile voljne vratiti svoje građane zbog tehničkih i pravnih poteškoća, političkih razloga i sigurnosnih problema. ${ }^{7}$ Evropske zemlje poput Francuske, Njemačke, Nizozemske, Norveške i Belgije odlučile su vratiti, gotovo isključivo, samo nekoliko djece bez roditelja vlastitih državljana koji su se pridružili IS-u. Kosovo je jedna od rijetkih zemalja u Evropi koja je do sada prihvatila grupnu repatrijaciju 110 državljana, od kojih su više od dvije trećine (74) djeca, uključujući djecu čiji je barem jedan roditelj državljanin Kosova u Siriji i Iraku. ${ }^{8}$ Krajem

decembra 2019. godine, Bosna i Hercegovina je također izvršila repatrijaciju 25 svojih državljana,

2 Ibid.

3 Syrian Arab Republic: North East Syria: Al Hol Camp," OCHA, 1. august 2019., https://reliefweb.int/sites/reliefweb.int/files/ resources/Al-Hol-Snapshot-SitRip-040819.pdf.

4 Keerthana Annamaneni, "For ISIS Children, Returning Home to Europe Meets Resistance," The New York Times, 15. august 2019., https://www.nytimes.com/2019/08/15/world/europe/isis-children-belgium.html.

5 Komisija Ujedinjenih nacija za istragu o Siriji, Escalating Violence and Waves of Displacement Continue to Torment Civilians during Eighth Year of Syrian Conflict (Ženeva: Vijeće Ujedinjenih nacija za ljudska prava, 2019.), https://www.ohchr.org/EN/ HRBodies/HRC/Pages/NewsDetail.aspx?NewsID=24972\&LangID=E.

6 Ibid.

7 Michael Birnbaum, "Months after the Fall of ISIS, Europe Has Done Little to Take Back Its Fighters," The Washington Post, 20. juni 2019., https://www.washingtonpost.com/world/europe/after-caliphate-collapsed-europe-has-done-little-to-takeback- those-who-joined-isis/2019/06/20/4bab9cc2-8bc4-11e9-b6f4-033356502dce story.html.

8 Fatos Bytyci, "Kosovo Brings Back Fighters, Families of Jihadists from Syria," Reuters, 20. april 2019., https://www.reuters. com/article/us-kosovo-syria/kosovo-brings-back-fighters-families-of-jihadists-from-syria-idUSKCN1RW003. 
među kojima je bilo 12 djece. ${ }^{9}$ lako 25 državljana BiH za koje je izvršena repatrijacija čine samo jednu desetinu ukupnog broja državljana BiH u sirijskim logorima (službeni izvori procjenjuju da takvih osoba ima 260), ${ }^{10}$ njihova repatrijacija je od velike važnosti. Spremnost Kosova i Bosne i Hercegovine, dvije inače male zemlje sa skromnim resursima, da olakšaju povratak svojih državljana, posebno djece, predstavlja signal da se uprkos brojnim objektivnim poteškoćama može skupiti politička volja za rješavanje ovog teškog pitanja na Zapadnom Balkanu.

Uprkos tome, druge zemlje u regiji većinom su iskazale nespremnost ili nedostatak planova za povratak svojih državljana. Do sada nijedna druga zemlja zapadnog Balkana nije javno objavila bilo kakav plan ili vremenski raspored za repatrijaciju. Jasna strategija za rješavanje ovog složenog izazova i dalje je nedostižna. Kurdski improvizirani kampovi i zatvori neće pružiti dugoročno rješenje za ovo hitno pitanje, posebno uzimajući u obzir da u kontingentu stranaca koji se tamo nalaze prevladavaju ranjive maloljetne osobe izložene poteškoćama pogodnim za radikalizaciju. ${ }^{11}$ Trenutna populacija stranih mladih osoba povezanih sa sukobom u Siriji zahtijeva proaktivno djelovanje, posebno uzimanje u obzir dobi i spola te odgovarajuća prilagođavanja reakcija politike u očekivanju njihove repatrijacije. To je posebno slučaj na Zapadnom Balkanu, koji u poređenju s većinom drugih evropskih država ima veći broj povratnika ili onih koji će vjerojatno biti vraćeni, a mnogo manje u pogledu resursa, kapaciteta i stručnosti dostupnih da se djelotvorno bave njima.

\section{Preporuke}

Nova istraživanja i programi o povratnicima iz Sirije i Iraka tek se počinju baviti izazovom koji predstavljaju maloljetni povratnici. Prilagođeni programi fokusirani na starosne i spolne faktore i dalje su rijetki. lako je iskustvo djelotvornog angažmana s djecom povratnicima iz Sirije i Iraka u inicijalnoj fazi, postepeno se javljaju početne dobre prakse iz napora u oblasti rehabilitacije i reintegracije. ${ }^{12}$ Korisna istraživanja i dobre prakse iz rehabilitacijskog rada s djecom vojnicima ili maloljetnicima izloženim ratnim traumama mogu također poboljšati djelotvorne političke odgovore za rješavanje problema rehabilitacije i reintegracije djece povratnika na Zapadnom Balkanu, u skladu s relevantnim konvencijama, međunarodnim ugovorima i protokolima kojim se definiraju prava djece.

\section{Proaktivno, transparentno i inkluzivno kreiranje politike}

$\rightarrow$ Usvojite proaktivan i inkluzivan pristup više agencija, obavezujući se na dugoročnu strategiju za rehabilitaciju i reintegraciju. Organi vlasti trebali bi proaktivno ulagati u višeagencijska partnerstva i programe koji su fleksibilni, adekvatno finansijski podržani i inkluzivni uz rano integriranje civilnog društva u proces. Međunarodni donatori i specijalizirane agencije trebali

9 "Authorities Say 25 Bosnians Sent Home from Camps in Syria," AP News, 19. decembar 2019., https://apnews.com/850b5ffb b045c65f1dfbbce52c9ff182.

10 "Bosnia: Citizens Who Fought for IS in Syria Can Return," AP News, 11. novembar 2019., https://apnews.com/818776caf4a44 b6f97d8eb5c285ace00.

11 Vijeće Ujedinjenih nacija za ljudska prava, Report of the Independent International Commission of Inquiry on the Syrian Arab Republic, A/HRC/42/51 (New York: Generalna skupština Ujedinjenih nacija, 2019.), https://www.securitycouncilreport.org/ atf/cf/\%7B65BFCF9B-6D27-4E9C-8CD3-CF6E4FF96FF9\%7D/a hrc 42 51.pdf.

Više informacija potražite u odjeljku „Prijedlog materijala za dodatno informiranje“ na kraju ove Bilješke o politici. 
bi osigurati dodatna sredstva i napore za razvoj kapaciteta u cilju rješavanja problema nedostatka resursa i stručnosti. Uz više od 400 djece i 150 žena koje su do danas vraćene iz Sirije i Iraka ${ }^{13}$, napori Kazahstana mogu pružiti uvide u takvu vrstu pristupa. Do kraja 2019. godine u toj zemlji je uspostavljeno 17 regionalnih prihvatnih i rehabilitacijskih centara ${ }^{14}$ za smještaj povratnika na neograničene vremenske periode, ovisno o individualnim potrebama i napretku deradikalizacije. ${ }^{15}$ Centri ne pružaju samo usluge smještaja, već obezbjeđuju i medicinsko i psihološko liječenje, obrazovanje, pravnu pomoć, terapiju kroz umjetnost i osposobljavanje za posao. ${ }^{16}$ Kurikulum je izrađen uz saradnju s grupom nevladinih organizacija, dok socijalni radnici i agencije vlade koordiniraju provođenje programa. ${ }^{17}$

$\rightarrow$ Dizajnirajte protokole za angažiranje prilagođene maloljetnim povratnicima, učinite ih javnim i decentralizirajte postupak implementacije gdje god je to moguće. Pristup uz angažiranje osmišljen u skladu s određenim potrebama maloljetnika vjerovatno će omogućiti učinkovitiji psihosocijalni oporavak i ubrzanu reintegraciju djece povratnika. Objavljivanje tih smjernica donijelo bi dodatnu transparentnost, odgovornost i podršku procesu. Decentralizirani pristup implementaciji koji vode lokalni organi vlasti i nevladine organizacije vjerojatno će podstaknuti povećani angažman i vlasništvo nad procesom rehabilitacije i reintegracije na nivou zajednice. Uprkos tome što je do početka 2020. godine vratila samo 17 maloljetnika ${ }^{18}$, uglavnom siročadi, Francuska je kreirala i objavila detaljne smjernice i modalitete za postupanje s francuskih i stranih maloljetnim povratnicima koji su se početkom 2017. vratili iz Sirije i Iraka. ${ }^{19}$ U tom strateškom dokumentu naglašava se vodeća uloga lokalnih organa vlasti i regionalnih ureda i uključuje se shema za koordinaciju i razmjenu informacija između agencija odgovornih za njenu implementaciju.

$\rightarrow$ Organizirajte rehabilitaciju i reintegraciju djece povratnika i pristupite joj kroz vizuru obrazovanja. Zbog razmatranja iz oblasti nacionalne sigurnosti, neki aspekti repatrijacije i rehabilitacije i reintegracije povratnika, posebno odraslih osoba, neizbježno su povezani s provođenjem zakona i krivično-pravnim postupcima. Međutim, za djecu su obrazovanje i stručno osposobljavanje neki od najvažnijih aspekata rehabilitacije i

13 "Zhusan Operation: 595 Kazakhstanis Repatriated from Syria," Kazinform International News Agency, 6. februar 2020., https://www.inform.kz/en/zhusan-operation-595-kazakhstanis-repatriated-from-syria a3611674.

Stevan Weine “Rehabilitating the IslamicState's Womenand Children Returnees in Kazakhstan," JustSecurity, 12. decembar 2019., https://www.justsecurity.org/67694/rehabilitating-the-islamic-states-women-and-children-returnees-in-kazakhstan/.

"39 Families Have Been Returned Back from Syria to Kazakhstan," Kazakhstan Today, 18. novembar 2019., https://www. kt.kz/eng/international affair/39 families have been returned back from syria to kazakhstan 1153667282.html

Ksenia Bondal, "Kazakhstan Rehabilitating Children Recently Returned from Syria, Iraq," Caravanserai, 8. januar 2019., http:// central.asia-ews.com/en GB/articles/cnmi ca/features/2019/01/08/feature-01.

Andrew E. Kramer, "Kazakhstan Welcomes Women Back from the Islamic State, Warily," The New York Times, 10. august 2019., https://www.nytimes.com/2019/08/10/world/europe/kazakhstan-women-islamic-state-deradicalization.html.

Benjamin Sportouch i Charles Deluermoz, "Enfants de jihadistes : 'Nous en avons rapatrié 17' en France, annonce Le Drian sur RTL," RTL, 2. februar 2020., https://www.rtl.fr/actu/politique/ enfants-de-jihadistes-nous-en-avons-rapatrie-17-en-franceannonce-le-drian-sur-rtl-7800014980.

19 Ured premijera Vlade Francuske, Instruction relative à la prise en charge des mineurs à leur retour de zone irako-syrienne, cirkularno pismo br. 5923/SG (Pariz: Vlada Francuske, mart 2017.), http://circulaires.legifrance.gouv.fr/ pdf/2017/03/ cir 41965.pdf. 
reintegracije jer nude put u novu budućnost, kao u programima reintegracije djece vojnika. ${ }^{20}$ Imajući to na umu, ministarstva obrazovanja pojedinačnih država Zapadnog Balkana, na primjer, mogu biti prikladnija i pozvanija od ministarstava unutrašnjih poslova kada je riječ o vođenju i koordinaciji rehabilitacije djece koja su uključena u nasilni ekstremistički sukob. Izbor ministarstva je važan jer odražava i javnosti prenosi cjelokupni mentalni sklop angažiranja vlade. U Kazahstanu je vlada za program rehabilitacije i reintegracije odlučila zadužiti Ministarstvo obrazovanja. Njihovo iskustvo može pružiti neke korisne uvide u tom pogledu. ${ }^{21}$

\section{Zaštitite i podržite dijete}

$\rightarrow$ Podržite mjere koje daju prioritet najboljem interesu djece povratnika i najbržoj razumnoj rehabilitaciji i reintegraciji u glavne tokove društva. Pravosudne institucije trebale bi djelovati u skladu s međunarodnim pravom i važećim standardima u oblasti maloljetničkog pravosuđa. U slučajevima kad je krivično gonjenje djece mlađe od 18 godina opravdano, potrebno je u skladu s Konvencijom o pravima djeteta razmotriti alternative pritvaranju prije suđenja i slanju u zatvor. ${ }^{22}$ Rezolucija Generalne skupštine 70/291 o Pregledu globalne protivterorističke strategije Ujedinjenih nacija bavi se ovom određenom temom i potrebno ju je konsultirati prilikom kreiranja odgovarajućih pravnih mehanizama. ${ }^{23}$

$\rightarrow$ Izvršite procjene rizika i potreba kako biste procijenili mentalnu dobrobit i nivo traume djece povratnika prije pružanja psihosocijalne podrške prilagođene individualnim potrebama. Djeca povratnici su bila izložena situacijama ekstremnog nasilja i u nekim su slučajevima možda pretrpjela ekstremno nasilje iz prve ruke. U drugim slučajevima su možda učestvovala u počinjenju nasilnih ekstremističkih djela. Agencije nadležne za javno zdravstvo trebale bi provoditi temeljite i periodične procjene kako bi svaki slučaj procijenile zasebno. ${ }^{24}$ Budući da su neka starija djeca povratnici vjerojatno bila podvrgnuta nasilnoj ekstremističkoj indoktrinaciji i obuci dok su bila u Siriji i Iraku, organi vlasti bi trebali procijeniti potencijalni rizik koji ona predstavljaju i pružiti specijaliziranu skrb za rješavanje njihove indoktrinacije i obuke prije prebacivanja takve djece u javno

20 Ured posebnog predstavnika generalnog sekretara za djecu i oružani sukob, Reintegration of Former Child Soldiers (New York: Sekretarijat Ujedinjenih nacija, 2018.), https://childrenandarmedconflict.un.org/wp-content/uploads/2018/09/ Reintergration-brochure-layout.pdf; Skënder Perteshi i Ramadan Ilazi, Unpacking Kosovo's Response to Returnees from the War Zones in Syria and Iraq (Priština: Kosovski centar za sigurnosne studije, 2020.), http://www.qkss.org/repository/docs/ violent-extremism-eng 978757.pdf.

Weine, "Rehabilitating the Islamic State's Women and Children Returnees in Kazakhstan."

Convention on the Rights of the Child (New York: Generalna skupština Ujedinjenih nacija, 1989), https://www.ohchr.org/ en/profes- sionalinterest/pages/crc.aspx; Ured Ujedinjenih nacija za borbu protiv terorizma (UNCCT), Children Affected by the Foreign-fighter Phenomenon: Ensuring a Child Rights-based Approach (New York: UNCCT, 2019.), https://www.un.org/ counterterrorism/ctitf/sites/www.un.org.counterterrorism.ctitf/files/ftf handbook web reduced.pdf.

23 Generalna skupština Ujedinjenih nacija, 70. zasjedanje, "Resolution 70/291 [The United Nations Global Counter-Terrorism Strategy Review]" (A/RES/70/291) 1. juli 2016., https://www.un.org/sc/ctc/news/ document/a-res-70-291-the-united-nations-global-counter-terrorism-strategy-review/.

24 Organizacija za sigurnost i saradnju u Evropi (OSCE), Non-custodial Rehabilitation and Reintegration in Preventing and Countering Violent Extremism and Radicalization That Lead to Terrorism A Guidebook for Policymakers and Practitioners in South-Eastern Europe (Beč, OSCE, 2020.), https://www.osce.org/secretariat/444838?download=true. 
obrazovno okruženje. Krajem aprila 2019. godine Kosovo je izvršilo repatrijaciju 74 maloljetne osobe iz Sirije. Do septembra su sva djeca školske dobi među tim povratnicima bila

spremna za polazak u školu. ${ }^{25}$ Budući da je njihovo učinkovito uključivanje u glavne tokove društva krajnji cilj napora na reintegraciji, upis djece povratnika u školu predstavlja pozitivan korak. Ipak, nejasno je koliku su prilagođenu psihološku i akademsku podršku ta djeca dobila prije upisivanja u javne škole nekoliko mjeseci nakon povratka.

$\rightarrow$ Provodite psihometrijske testove za procjenu intelektualnog razvoja djece povratnika kako bi se osiguralo valjano pozicioniranje u obrazovni sistem i pružila akademska pomoć po potrebi. Ti napori vjerojatno biti učinkovitiji ako djeca ne budu institucionalizirana, ali dobivaju akademsko obrazovanje i psihološku pomoć kod kuće, možda putem mobilnih timova stručnjaka. To može pomoći u izbjegavanju osjećaja neadekvatnosti, stigme i potencijalne marginalizacije sve dok povratnicima boravak u novom socijalnom okruženju ne postane ugodniji. Na primjer, u Francuskoj, nakon što tužilac i sudija za maloljetnike procijene slučaj pojedinačnog djeteta povratnika, maloljetnici se podvrgavaju somatskom i psihološkom pregledu uz skrb socijalnih službi. Odluke o školovanju donose se u dogovoru s akademskim direktorom Nacionalnih obrazovnih službi, obrazovnim institucijama i stručnjacima iz prakse koji provode i nadgledaju napore na rehabilitaciji i reintegraciji. ${ }^{26}$

\section{Zaključak}

Uspješna rehabilitacija i reintegracija djece povratnika u konačnici će zahtijevati usvajanje holističke strategije psihosocijalne podrške uz bavljenje svim aspektima njihove socijalne interakcije i reintegracije u kući, školi i zajednici. S tim na umu, na napredak svakog djeteta povratnika u procesu rehabilitacije i reintegracije umnogome će uticati svjetonazor i stav roditelja i rodbine koji žive s njima. Stoga bi programi trebali pružiti širu podršku za rješavanje pitanja radikalizacije do nivoa nasilja i traume u cijeloj porodici. Također, nastavnici i drugi stručnjaci iz prakse uključeni u proces obrazovanja i rehabilitacije djece povratnika trebali bi proći obuku o svijesti o traumi i dobiti informacije o procesu radikalizacije, uključujući i načine odgovaranja na znakove zabrinjavajućeg ponašanja i upute o tome gdje tražiti dodatnu podršku. Uz poboljšano znanje, vještine i alate za rješavanje zabrinutosti zajednica koje primaju povratnike i stvarnosti povratničkih iskustava, države Zapadnog Balkana mogu olakšati mirniju i sigurniju tranziciju povratnika u glavne tokove društva.

25 Taulant Qenaj, "Fëmijët e Kthyer Nga Siria, Sërish Në Shkolla," Radio Evropa e Lirë, 27. august 2019., https://www.evropaelire. org/a/femijet-e-kthyer-nga-siria-shkollim-/30130050.html.

26 Ured premijera Vlade Francuske, Instruction relative à la prise en charge des mineurs à leur retour de zone irako-syrienne, cirkularno pismo br. 5923/SG. 


\section{Prijedlog materijala za dodatno informiranje, po temama}

\section{O vrbovanju i iskorištavanju djece od strane terorista}

Bloom, Mia i John Horgan. Small Arms: Children and Terrorism. Ithaca, New York: Cornell University Press, 2019.

Ured Ujedinjenih nacija za droge i kriminal (UNODC). Handbook on Children Recruited and Exploited by Terrorist and Violent Extremist Groups: The Role of the Justice System. Beč: UNODC, 2017. https:// www.unodc.org/documents/justice-and-prison-reform/Child-Victims/Handbook on Children Recruited and Exploited by Terrorist and Violent Extremist Groups the Role of the Justice System.E.pdf.

\section{O djeci povezanoj s terorističkim organizacijama u Siriji i Iraku}

Cook, Joana i Gina Valle. "From Daesh to 'Diaspora' II: The Challenges Posed by Women and Minors After the Fall of the Caliphate." CTC Sentinel 12, br. 6 (juli 2019.): 30-45. (juli 2019.) https://ctc.usma. edu/daesh-diaspora-challenges-posed-women-minors-fall-caliphate/.

\section{0 rehabilitaciji i reintegraciji djece}

Meines, Marije, Merel Molenkamp, Omar Ramadan i Magnus Ranstorp. RAN Manual: Responses to Returnees: Foreign Terrorist Fighters and their Families. Amsterdam: Mreža za svjesnost o radikalizaciji (RAN) Centar izvrsnosti, 2017. https://ec.europa.eu/home-affairs/sites/homeaffairs/ files/ ran br a4 m10 en.pdf.

Globalni forum protiv terorizma (GCTF). Good Practices on Addressing the Challenge of Returning Families of Foreign Terrorist Fighters. GCTF, 2018. https://www.thegctf.org/Portals/1/Docu- ments/ Framework\%20Documents/2018/GCTF-Good-Practices-on-Returning-Families-of-FTFs ENG. pdf?ver=2018-09-25-101427-323.

Ujedinjenje nacije. Key Principles for the Protection, Repatriation, Prosecution, Rehabilitation and Reintegration of Women and Children with Links to United Nations Listed Terrorist Groups. Ujedinjenje nacije, 2019. https://www.un.org/counterterrorism/ctitf/sites/www.un.org. counterterrorism.ctitf/files/Key\%20 Principles\%20-\%20April\%202019 0.pdf.

Ured Ujedinjenih nacija za borbu protiv terorizma (UNCCT). Children Affected by the Foreign-fighter Phenomenon: Ensuring a Child Rights-based Approach. New York: UNCCT, 2019. https://www. un.org/counter- terrorism/ctitf/sites/www.un.org.counterterrorism.ctitf/files/ftf handbook web reduced.pdf

Ured Ujedinjenih nacija za droge i kriminal (UNODC). Roadmap on the Treatment of Children Associated with Terrorist and Violent Extremist Groups. Beč: UNODC, 2019. https://indd.adobe.com/ view/61793921-8dc6-4fc2-9e46-b27c6390fff2.

van der Heide, Liesbeth i Jip Geenen. Children of the Caliphate: Young IS Returnees and the Reintegration Challenge. Hag: Međunarodni centar za borbu protiv terorizma - Hag, 2017. https://icct. nl/wpcontent/uploads/2017/08/ICCT-vanderHeide-Geenen-Children-of-the-Caliphate-2.pdf.

O izazovima s kojim se suočavaju stručnjaci iz prakse prilikom rada s djecom povratnicima

Mreža za svjesnost o radikalizaciji (RAN). Child Returnees from Conflict Zones. Amsterdam: RAN Centar izvrsnosti, 2016. https://ec.europa.eu/home-affairs/sites/homeaffairs/files/what-we-do/ networks/radicalisation awareness network/ran-papers/docs/issue paper child returnees from conflict zones 112016 en.pdf. 


\section{Izvori}

"39 Families Have Been Returned Back from Syria to Kazakhstan." Kazakhstan Today, 18. novembar 2019. https://www.kt.kz/eng/ international affair/39 families have been returned back from syria to kazakhstan 1153667282.html.

Annamaneni, Keerthana. "For ISIS Children, Returning Home to Europe Meets Resistance." The New York Times, 15. august 2019. https://www.nytimes.com/2019/08/15/world/europe/isis-children-belgium.html.

"Authorities Say 25 Bosnians Sent Home from Camps in Syria." AP News, 19. decembar 2019. https://apnews.com/850b5ffbb045 c65f1dfbbce52c9ff182.

Birnbaum, Michael. "Months after the Fall of ISIS, Europe Has Done Little to Take Back Its Fighters." The Washington Post, 20. juni 2019. https://www.washingtonpost.com/world/europe/after-caliphate-collapsed-europe-has-done-little-to-take-backthose-who-joined-isis/2019/06/20/4bab9cc2-8bc4-11e9-b6f4-033356502dce story.html.

Bondal, Ksenia. "Kazakhstan Rehabilitating Children Recently Returned from Syria, Iraq." Caravanserai, 8. januar 2019. http:// central.asia-ews.com/en GB/articles/cnmi ca/features/2019/01/08/feature-01.

"Bosnia: Citizens Who Fought for IS in Syria Can Return." AP News, 11. novembar 2019. https://apnews.com/818776caf4a44b6f $\underline{97 \mathrm{~d} 8 \mathrm{eb} 5 \mathrm{c} 285 \mathrm{ace} 00 .}$.

Bytyci, Fatos. "Kosovo Brings Back Fighters, Families of Jihadists from Syria." Reuters, 20. april 2019. https://www.reuters.com/ article/us-kosovo-syria/kosovo-brings-back-fighters-families-of-jihadists-from-syria-idUSKCN1RW003.

Kramer, Andrew E. "Kazakhstan Welcomes Women Back from the Islamic State, Warily." The New York Times, 10. august 2019. https://www.nytimes.com/2019/08/10/world/europe/kazakhstan-women-islamic-state-deradicalization.html.

Ured posebnog predstavnika generalnog sekretara za djecu i oružani sukob. Reintegration of Former Child Soldiers. New York: Sekretarijat Ujedinjenih nacija, 2018. https://childrenandarmedconflict.un.org/wp-content/uploads/2018/09/Reintergrationbrochure-layout.pdf.

Organizacija za sigurnost i saradnju u Evropi (OSCE). Non-custodial Rehabilitation and Reintegration in Preventing and Countering Violent Extremism and Radicalization That Lead to Terrorism A Guidebook for Policymakers and Practitioners in South-Eastern Europe. Beč, OSCE, 2020. https://www.osce.org/secretariat/444838?download=true.

Perteshi, Skënder i Ramadan Ilazi. Unpacking Kosovo's Response to Returnees from the War Zones in Syria and Iraq. Priština: Kosovski centar za sigurnosne studije, 2020. http://www.akss.org/repository/docs/violent-extremism-eng 978757.pdf.

Ured premijera Vlade Francuske. Instruction relative à la prise en charge des mineurs à leur retour de zone irako-syrienne, cirkularno pismo br. 5923/SG. Pariz: Vlada Francuske, mart 2017. http://circulaires.legifrance.gouv.fr/ pdf/2017/03/cir 41965.pdf.

Qenaj, Taulant. "Fëmijët e Kthyer Nga Siria, Sërish Në Shkolla." Radio Evropa e Lirë, 27. august 2019. https://www.evropaelire. org/a/femijet-e-kthyer-nga-siria-shkollim-/30130050.html.

Shtuni, Adrian. "Western Balkans Foreign Fighters and Homegrown Jihadis: Trends and Implications, Combating Terrorism." CTC Sentinel 12, br. 7 (13. august 2019):18-24. https://ctc.usma.edu/western-balkans-foreign-fighters-homegrown-jihadistrends-implications/.

Sportouch, Benjamin i Charles Deluermoz. "Enfants de jihadistes: 'Nous en avons rapatrié 17' en France, annonce Le Drian sur RTL.” RTL, 2. februar 2020. https://www.rtl.fr/actu/politique/enfants-de-jihadistes-nous-en-avons-rapatrie-17-en-franceannonce-le-drian-sur-rtl-7800014980.

"Syrian Arab Republic: North East Syria: Al Hol Camp." OCHA, 1. august 2019. https://reliefweb.int/sites/reliefweb.int/files/ resources/Al-Hol-Snapshot-SitRip-040819.pdf. 
Komisija Ujedinjenih nacija za istragu o Siriji. Escalating Violence and Waves of Displacement Continue to Torment Civilians during Eighth Year of Syrian Conflict. Ženeva: Vijeće Ujedinjenih nacija za ljudska prava, 2019. https://www.ohchr.org/EN/HRBodies/

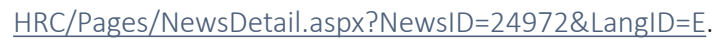

Generalna skupština Ujedinjenih nacija. Convention on the Rights of the Child. New York: Generalna skupština Ujedinjenih nacija, 1989. https://www.ohchr.org/en/professionalinterest/pages/crc.aspx.

- - , 70.zasjedanje. "Resolution70/291[TheUnited Nations GlobalCounter-TerrorismStrategyReview]”(A/RES/70/291)1.juli2016. https://www.un.org/sc/ctc/news/document/a-res-70-291-the-united-nations-global-counter-terrorism-strategy-review/.

Vijeće Ujedinjenih nacija za ljudska prava. Report of the Independent International Commission of Inquiry on the Syrian Arab Republic, A/ HRC/42/51. New York: Generalna skupština Ujedinjenih nacija, 2019. https://www.securitycouncilreport.org/atf/ cf/\%7B65BFCF9B- 6D27-4E9C-8CD3-CF6E4FF96FF9\%7D/a hrc 42 51.pdf.

Ured Ujedinjenih nacija za borbu protiv terorizma (UNCCT). Children Affected by the Foreign-fighter Phenomenon: Ensuring a Child Rights-based Approach. New York: UNCCT, 2019. https://www.un.org/counterterrorism/ctitf/sites/www.un.org. counterterrorism.ctitf/files/ftf handbook web reduced.pdf.

Weine, Stevan. "Rehabilitating the Islamic State's Women and Children Returnees in Kazakhstan." Just Security, 12. decembar 2019. https://www.justsecurity.org/67694/rehabilitating-the-islamic-states-women-and-children-returnees-in-kazakhstan/.

"Zhusan Operation: 595 Kazakhstanis Repatriated from Syria." Kazinform International News Agency, 6. februar 2020. https:// www.inform.kz/en/zhusan-operation-595-kazakhstanis-repatriated-from-syria a3611674. 


\section{O Bilješci}

Autor: Adrian Shtuni, direktor kompanije Shtuni Consulting LLC je stručnjak za inostranu politiku, sigurnost i strateške komunikacije s regionalnim fokusom na Zapadni Balkan. Radi kao konsultant za agencije vlade SAD, akademske institucije i međunarodne organizacije u Sjedinjenim Američkim Državama, Evropi i Aziji u oblastima suzbijanja nasilnog ekstremizma, djelovanja protiv terorizma, političkog rizika, suzbijanja inostrane propagande $i$ dezinformacija i drugih transnacionalnih prijetnji.

Stavovi izneseni u ovoj publikaciji predstavljaju mišljenje autora. Oni nužno ne odražavaju stavove organizacije RESOLVE Network, Instituta za mir SAD ili bilo kojeg organa vlasti SAD-a.

RESOLVE NETWORK bolje istraživanje.djelovanje na osnovu kvalitetnih informacija.unaprijeđena politika o nasilnom ekstremizmu. www.resolvenet.org 